\title{
Polymeric Nanoparticles Stabilized by Surfactants: Controlled Phase Separation Approach
}

\author{
Sergey K. Filippov, Jiri Panek and Petr Stepanek \\ Institute of Macromolecular Chemistry, Academy of Sciences of the Czech Republic, \\ Czech Republic
}

\section{Introduction}

It is accepted nowadays that the self-assembly or self-organization occurs in a system when two types of interactions exist simultaneously between various elements of a system - a short-range attraction and a long-range repulsion. If a combination of such interactions is manifested in a system, equilibrium nanostructures/nanoparticles could occur. This general principle applies for many different systems - e.g., liquid crystals, ferrofluids, lyotropic systems, surfactants and polymers. Polymers and copolymers in good solvent are widely used for creation of self-assembled nanoparticles in solution since they offer an extremely wide range of different monomers and compositions, the possibility to vary the polymer chain length and use tailor-made polymers for producing materials with specific properties and functionalities. For such polymers, no additives are required to form equilibrium nanoparticles.

This chapter reviews another technique of creating self-assembled and self-organized polymeric nanoparticles - controlled phase separation approach. Such approach exploits mutual interactions of a polymers and surface active molecules (surfactants or amphiphilic block copolymers) in a common solvent. We shall explore particularly dilute systems where various types of nanoparticles will be investigated. The nanoparticles will be studied keeping in mind their possible applications, especially for biological purposes encapsulation and delivery of active substances in the case of particles and immobilization.

\section{Background}

The common approach applied to all types of physical systems described below is based on controlling the extent of macrophase separation that occurs in a mixture of two compounds (solvent and polymer) that became immiscible or incompatible as a result of a change of an external variable. This parameter can be temperature, $\mathrm{pH}$ or addition of a another solvent, in principle it could also be a change in pressure but the latter is not very practical since usually large pressure changes are needed to achieve relatively small changes in phase diagrams. 
A phase diagram for a polymer A/polymer B or polymer/solvent system is schematically represented in Fig. 1. In the classical case the energy of the system is given by enthalpic and entropic contributions and the interaction parameter $\chi$ is given by the Flory-Huggins relation $\chi=a / T+b$ where $\mathrm{T}$ is absolute temperature and $a$ and $b$ are specific for the polymer/polymer or polymer/solvent pair. For more complex systems, a third term $\chi_{\mathrm{s}}$ has to be included:

$$
\chi=a / T+b+\chi_{s}
$$

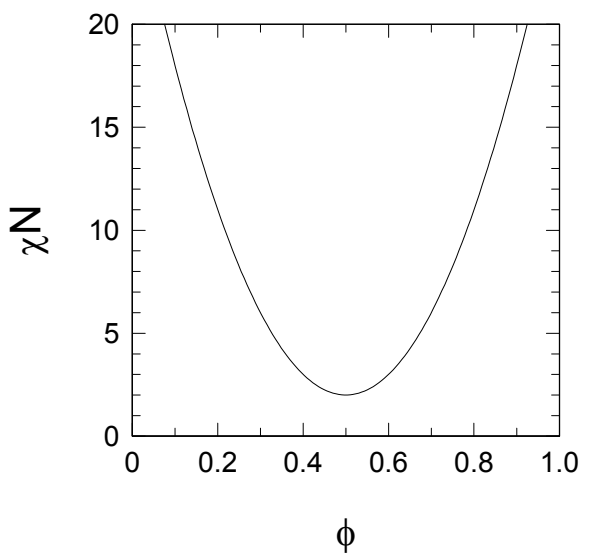

Fig. 1. Schematic phase diagram for a polymer A/polymer B or polymer/solvent. $\phi$ is the volume fraction of the first component of the system, $\mathrm{N}$ the number of monomers in the polymer chain and $\chi$ the interaction parameter describing the strength of interaction between polymer A and B or between the polymer and solvent.

In this simple representation the third term includes all additional interactions in the system, in particular the effect of different temperature expansions of the system components and that of various specific interactions in the system (hydrogen bonds, ionic interactions, ...) that may be dominant compared to the enthalpic/entropic terms $a, b$.

Once a macrophase separation has been initiated, the spatial extent of inhomogeneities produced by nucleation or spinodal decomposition is controlled by addition of amphiphilic molecules chosen in such a way that one part of this amphiphile interacts attractively with the nucleated material while the other part interacts attractively with the surrounding solvent. The surface of the nucleated material then becomes covered with the amphiphilic molecules which effectively terminate the phase separation and stabilizes the system in a dispersed state. The formation of nanoparticles is always driven by thermodynamics (increase of $\chi$-parameter in Eq. (1)) but controlled by specific factors of interaction with the amphiphilic molecules including kinetic and hydrodynamic effects. Assessment of these effects and their importance for nanoparticles preparation is a primary goal in this manuscript. In the following chapter we will describe several systems where this approach can be realized:

- Controlled phase separation induced by a change in temperature. 
- Controlled phase separation induced by a change of solvent

- Controlled phase separation induced by a change in $\mathrm{pH}$

\section{Experimental methods}

To observe and to prove the formation of well defined nanoparticles we have exploited a variety of methods such as static and dynamic light scattering (SLS/DLS), small-angle neutron and X-ray scattering (SANS/SAXS) and Cryo-TEM methods.

Since kinetic factors are involved into formation of nanoparticles created by controlled phase separation method we have examined the nucleation and growth of polymeric nanoparticles using the stopped-flow technique combined with SAXS on the time scale of milliseconds.

\subsection{Small-Angle Neutron Scattering (SANS)}

SANS experiments were performed at CEA-Saclay on the spectrometer PAXY of the Laboratoire Leon-Brillouin. Measurements were run on a $128 \times 128$ multidetector (pixel size $0.5 \times 0.5 \mathrm{~cm}$ ) using a non-polarized, monochromatic (wavelength $\lambda$ set by a velocity selector) incident neutron beam collimated with circular apertures for two sample-to-detector distances, namely, $1 \mathrm{~m}$ (with $\lambda=0.6 \mathrm{~nm}$ ) and $7 \mathrm{~m}$ (with $\lambda=0.8 \mathrm{~nm}$ ). With such a setup, the investigated range of scattering wave vector modulus was $5.9 \times 10^{-2}$ to $4.3 \mathrm{~nm}^{-1}$. In all the cases reported in this paper, the two-dimensional scattering patterns were isotropic so that they were azimuthally averaged to yield the dependence of the scattered intensity $I_{s}(q)$ on the scattering vector $q$. Data were corrected for background scattering and detector efficiency. Intensities of neutron scattering are given in arbitrary units.

\subsection{Dynamic and Static Light Scattering (DLS/SLS)}

Static light scattering measurements were carried out on an ALV-6010 instrument equipped with a $22 \mathrm{~mW} \mathrm{He}-\mathrm{Ne}$ laser in the angular range $30-150^{\circ}$. Dynamic light scattering measurements were carried out at $90^{\circ}$ angle. The obtained correlation functions were analyzed by REPES (Jakes, 1995) analytical software providing a distribution function, $G\left(R_{\mathrm{h}}\right)$ of hydrodynamic radii $R_{\mathrm{h}}$. To account for the logarithmic scale on the $R_{\mathrm{h}}$ axis, all DLS distribution diagrams are shown in the equal area representation, $R_{\mathrm{h}} G\left(R_{\mathrm{h}}\right)$. The static light scattering data were analyzed by a Zimm plot:

$$
\frac{K c}{R(q)}=\frac{1}{M_{w}}+\frac{R_{G}^{2} q^{2}}{3 M_{w}}
$$

where $R(q)$ is the Rayleigh ratio of the scattering intensity, $q=(4 \pi n / \lambda) \sin \Theta / 2$ is the scattering vector, $\lambda$-wave length in the medium, $\theta$ - scattering angle between the incident and the scattered beam, $K$ is a contrast factor containing the optical parameters, $c$ is a particle concentration, $M_{w}$ is the weight average of the molar mass of the particles, and $R_{G}$ is their radius of gyration. The concentration dependence was neglected which was acceptable because of the low concentrations of the solutions. 


\subsection{Cryo-transmission electron microscopy - Cryo-TEM}

To carry out a Cryo-TEM experiment, a drop of the solution under study was placed on a pretreated copper grid which was coated with a perforated polymer film. Excess solution was removed by blotting with a filter paper. The preparation of the sample film was done under controlled environment conditions, i.e., in a chamber at a constant temperature of $25^{\circ} \mathrm{C}$ and with a relative humidity of $98-99 \%$ to avoid evaporation of the liquid. Rapid vitrification of the thin film was achieved by plunging the grid into liquid ethane held just above its freezing point. The sample was then transferred to the electron microscope, a Zeiss 902A instrument (Carl Zeiss NTS, Oberkochen, Germany), operating at an accelerating voltage of $80 \mathrm{kV}$ and in zero-loss bright-field mode. The temperature was kept below -165 ${ }^{\circ} \mathrm{C}$ and the specimen was protected against atmospheric conditions during the entire procedure to prevent sample perturbation and formation of ice crystals. The resolution in this method was 3-5 nm. Digital images were acquired with a BioVision Pro-SM Slow Scan CCD camera (Proscan electronische systeme, GmbH, Germany). iTEM software (Olympus Soft Imaging Solutions, GmbH, Germany) was used for image processing. The polymer concentration used was $5 \cdot 10^{-3} \mathrm{~g} \mathrm{~mL}^{-1}$.

\subsection{Small angle X-ray scattering - SAXS}

All time-resolved SAXS (TR-SAXS) experiments were performed on the high brilliance beam line ID02 at the ESRF (Grenoble, France). The SAXS setup is based on a pinhole camera with a beam stop placed in front of a two-dimensional detector (X-ray image intensifier coupled to a CCD camera). The X-ray scattering patterns were recorded on the detector that was located $2 \mathrm{~m}$ from the sample, using a monochromatic incident $X$-ray beam $(\lambda=0.1 \mathrm{~nm})$. The available wave vector range was $0.04-2.71 \mathrm{~nm}^{-1}$. Data acquisition and counting of the time $t$ was hardware-triggered within $1 \mathrm{~ms}$ before the final mixing process was initiated. SAXS data were acquired with an exposure time of $50 \mathrm{~ms}$ per frame.

The fast mixing experiments were performed using a stopped-flow device (SFM-3, BioLogic) that has been specifically adapted for SAXS experiments. The device was thermostated at $25.0 \pm 0.5^{\circ} \mathrm{C}$

\section{Controlled phase separation induced by a change in temperature}

To fulfill this task we have exploited the phase separation of thermally sensitive PNIPAM polymer on heating above the lower critical solubility temperature (LCST). PNIPAM is a typical temperature-sensitive polymer that has LCST around of $32^{\circ} \mathrm{C}$ (detailed information on pure PNIPAM, can be found in the review (Aseyev et al., 2010) and references therein). Heating of aqueous solution of PNIPAM above LCST will initialize coil-to-globule transformation with following precipitation of the polymer. Such macrophase separation could be terminated if surface active molecules are presented in solution. Earlier we have demonstrated that well defined nanoparticles of PNIPAM could be prepared in presence of ionic and non-ionic surfactants' (SDS, CTAB, Brij98, Brij97) (Konak et al., 2007). The effect of PNIPAM and surfactant concentration, and molecular weight of PNIPAM on nanoparticle parameters and on the phase transition temperature of PNIPAM solutions was investigated. It was proposed that the structure of particles is supposed to be similar to block copolymer micelles. Hydrophobic PNIPAM molecules form the insoluble core of particles and their 
hydrophilic shell consists of hydrophilic parts of surfactants. An intermediate shell at the core-shell interface contains both the hydrophobic parts of surfactants and PNIPAM chains. The feature of that research is that in contrast to previous studies, where surfactants were used in excess, lower concentrations of surfactants were used.

To validate the proposed model, for PNIPAM and SDS system, a contrast variation study was performed by SANS. It is important to note here that the system studied in our research is different from a so-called mesoglobule state that was also observed (Siu et al., 2003; (Aseyev et al., 2005; Kujawa et al., 2006a; Kujawa et al., 2006b) for PNIPAM. It was established in variety of papers that PNIPAM macromolecules of high molar masses on very diluted solutions might undergo through intermediate mesoglobule state with increasing of temperature above LCST. These mesoglobules are aggregates of PNIPAM molecules that consist of one or more macromolecules. They are metastable particles that are stabilized either by electrostatic or steric interactions (Kujawa et al., 2006b). No surfactant is required. Nevertheless when PNIPAM concentration in solution is rather high macroscopic precipitation occurs. In this case, surface active molecules are needed to create stable polymeric nanoparticles.

Three types of nanoparticles were tested: $(i)$ deuterated d7-PNIPAM + protonated SDS in a $72 \% \mathrm{D}_{2} \mathrm{O} / 28 \% \mathrm{H}_{2} \mathrm{O}$ volume mixture where the coherent scattering originates only from the surfactant. (ii) protonated PNIPAM + protonated SDS in pure $\mathrm{D}_{2} \mathrm{O}$ where the scattering comes from the polymer and the surfactant. The whole nanoparticle should be visible. (iii) protonated PNIPAM + deuterated d25-SDS in $\mathrm{D}_{2} \mathrm{O}$. The scattering length density of the deuterated surfactant is almost matched by $\mathrm{D}_{2} \mathrm{O}$. In this case most of the scattering is produced by the polymer. The experiments have been conducted at $\mathrm{T}=42{ }^{\circ} \mathrm{C}$.

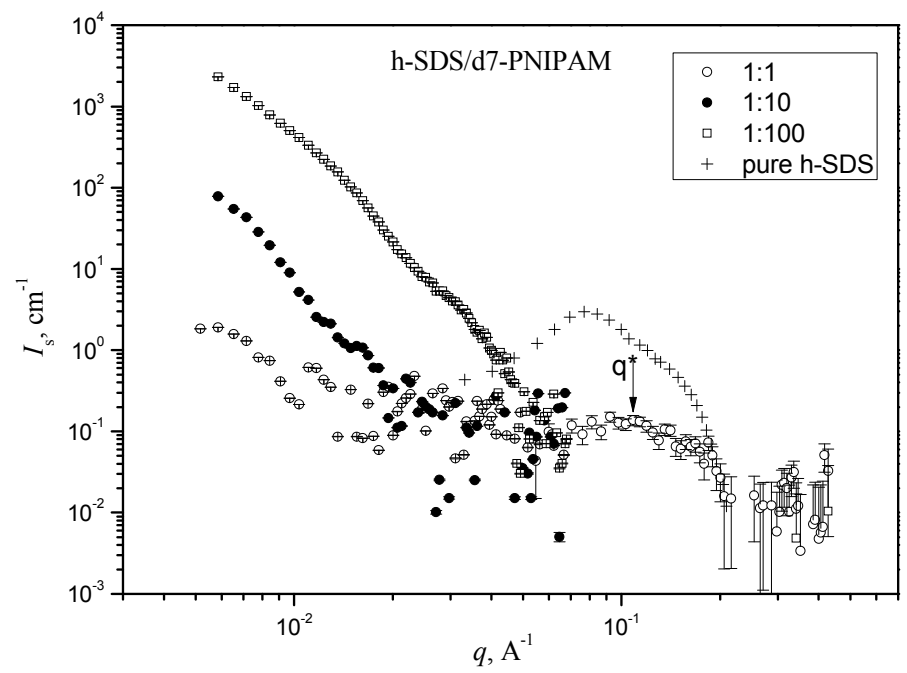

Fig. 2. Scattered intensity $I_{\mathrm{s}}$ as a function of the scattering vector $q$ for systems $\mathrm{d} 7$ -

PNIPAM/h-SDS sample, $c_{\text {d7-PNIPAM }}=5 \mathrm{~g} / \mathrm{L} ;(\circ) c_{\text {SDS }} /$ CPNIPAM $_{\text {PIP }}=1: 1 ;(\bullet) c_{\text {SDS }} /$ CPNIPAM $_{\text {PAM }}=1: 10 ;(\square)$ $c_{\text {SDS }} /$ CPNIPAM $=1: 100 ;(+)$ pure SDS. Data are taken from the reference (Lee \& Cabane, 1997). 
Earlier Cabane and Lee in their pioneer work have investigated similar the PNIPAM-SDS system by SANS (Lee \& Cabane, 1997) . The polymer molar mass that have been used in their study was $1 \cdot 10^{6} \mathrm{~g} /$ mole and concentration of solution was mainly $30 \mathrm{~g} / \mathrm{L}$. To avoid a mesoglobule state we have selected the h-PNIPAM with $\mathrm{M}_{\mathrm{w}}=1.88 \cdot 10^{5} \mathrm{~g} / \mathrm{mole}$ and $\mathrm{d} 7$ PNIPAM with $\mathrm{M}_{\mathrm{w}}=3.6 \cdot 10^{5} \mathrm{~g} /$ mole that is somewhat smaller than the one used by Cabane et.al. For the same reason, concentration of PNIPAM in all solution was kept of $5 \mathrm{~g} / \mathrm{L}$. Our work is thus a research on a similar system with different conditions.

Fig. 2-4 represents the data for different surfactant-to-polymer ratios. For all systems, the scattered intensity extrapolated to zero $q$ is increasing with decrease of the ratio. In other words, the growth of colloidal nanoparticles is observed with decrease of surfactant-to polymer ratio. One can see continuous evolution of the characteristic features of colloids.

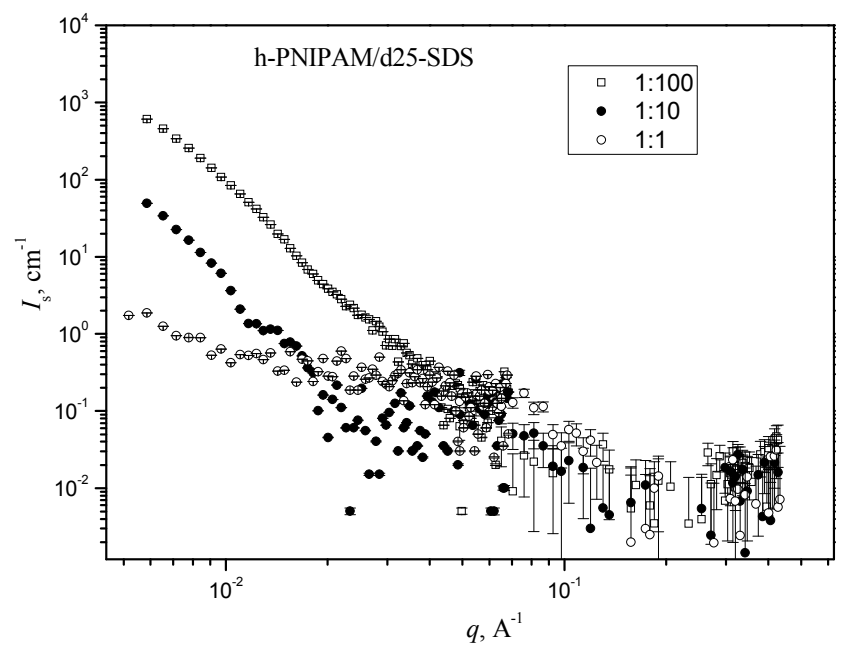

Fig. 3. Scattered intensity $I_{\mathrm{s}}$ as a function of the scattering vector $q$ for systems hPNIPAM/d25-SDS sample, $c_{\text {-PNIPAM }}=5 \mathrm{~g} / \mathrm{L} ;(\circ)$ CSDS $_{\text {CPNIPAM }}=1: 1 ;(\bullet)$ CSDS $_{\text {CPNIPAM }}=1: 10 ;(\square)$ $c_{\text {SDS }} /$ CPNIPAM $=1: 100$

\section{1 h-SDS/d7-PNIPAM}

When a surfactant is protonated, coherent scattering comes only from the surfactant in a $72 \% \mathrm{D}_{2} \mathrm{O} / 28 \% \mathrm{H}_{2} \mathrm{O}$ volume mixture. At low $q$, a $q^{-4}$ decay is visible at $c_{\text {SDS }} / c_{\text {PNIPAM }}=1: 100$ (Fig. 2). At high $q$ a signal is too low. For comparison reason, the scattering of pure SDS micelles is presented on Fig. 2. No peaks that correspond to the distance between consecutive SDS micelles at high $q$ range observed by Cabanne and Lee[8] (located at $q$ of about $0.1 \AA^{-1}$ ) appear on the graph. We conclude that all surfactant molecules are uniformly incorporated inside of a colloidal particle or on its surface. It is worth to note that such strong q dependence indicates that the surfactant forms big structures. At $c_{\text {SDS }} / c_{\text {PNIPAM }}=1: 1$, one can see that the scattering at low $q$ is week and simultaneously a peak at high $q$ range appears $\left(q^{*}=0.11 \AA^{-1}\right)$. Obviously, colloidal particles are completely dissolved now; a pearl-necklace complex exists with SDS micelles bound to a polymer chain with the distance of $58 \AA \AA\left(\mathrm{d}=2 \Pi / q^{*}\right)$. That finding is in good agreement with results of Cabanne where such distance was about $63 \AA$ 


\section{2 h-PNIPAM/d25-SDS}

Similar features are observed for the system where the PNIPAM is only visible. Again, the formation of nanoparticles could be monitored by the growth of the scattering intensity with decrease of the composition ratio. No peaks at high $q$ range observed are visible in this case. We conclude that PNIPAM is also uniformly distributed inside a nanoparticle.

\section{3 h-PNIPAM/h-SDS}

In this case both the polymer and the surfactant are visible in SANS.

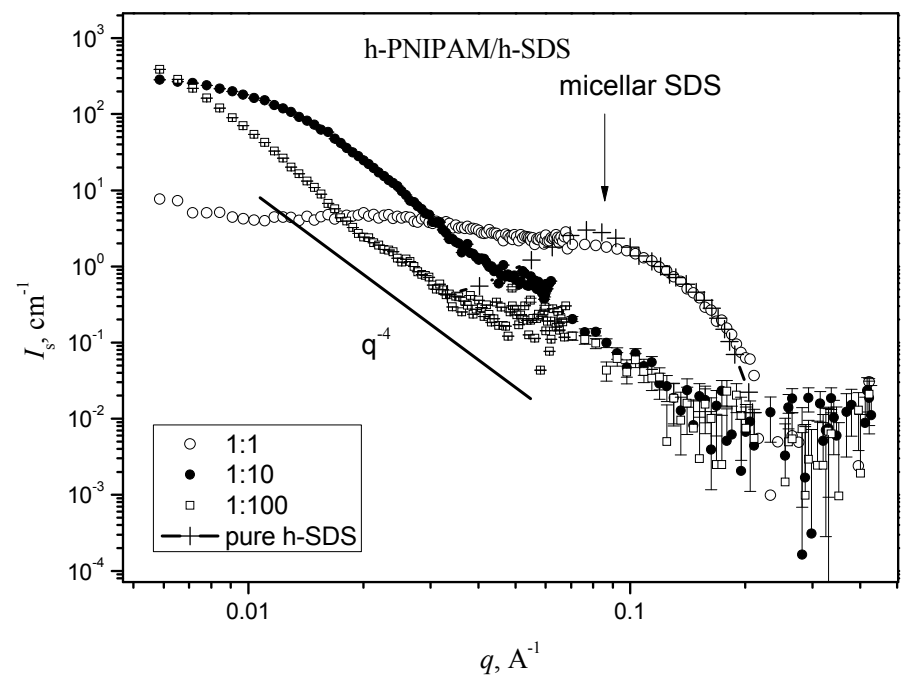

Fig. 4. Scattered intensity $I_{\mathrm{s}}$ as a function of the scattering vector $q$ for systems hPNIPAM/h-SDS sample, $c_{\text {-PNIPAM }}=5 \mathrm{~g} / \mathrm{L} ;(\circ) c_{\text {SDS }} / c_{\text {PNIPAM }}=1: 1 ;(\bullet) c_{\text {SDS }} /$ CPNIPAM $=1: 10 ;(\square)$ $c_{\text {SDS }} /$ c $_{\text {PNIPAM }}=1: 100 ;(+)$ pure SDS. Data are taken from reference (Lee \& Cabane, 1997).

The scattering curve at $c_{\mathrm{SDS}} / \mathrm{C}_{\mathrm{PNIPAM}}=1: 100$ begins at low $q$ at high intensity; then it curves downward and continuous with $q^{-4}$ decay (Fig. 4). This part of the scattering curve corresponds the scattering from colloidal particles. Fitting the scattering curves by formfactor of a hard sphere with Schultz-Zimm distribution provides $R_{\mathrm{g}}$ values of nanoparticles. Obtained values nanoparticles are 216, and $96 \AA$ for ratios 1:100 and 1:10, respectively, giving corresponding outer radii 279 , and $124 \AA$. Polydispersity value obtained from the fitting routine was 0.37 and 0.44 , respectively. Cabanne et. al. reported the similar value of about 0.5 . Such high numbers imply strong polydispersity in size for nanoparticles in solution.

At $c_{\text {SDS }} /$ CPNIPAM $_{\text {PNI }}=1: 1$ the scattering is flat at low $q$ (Fig. $4,5 \mathrm{a}, \mathrm{b}$ ) as it could be visible from a comparison with the spectra of samples made at lower ratios (1:10 and 1:100). At high $q$, one can see a plateau and, beyond $q=0.1 \AA^{-1}$, a steeper decay. This spectrum is identical to the scattering from a micellar solution of SDS at the same concentration in the absence of polymer (Fig. 4, 5a). In particular, the peak position matches the average intermicellar distance in pure SDS solutions. 

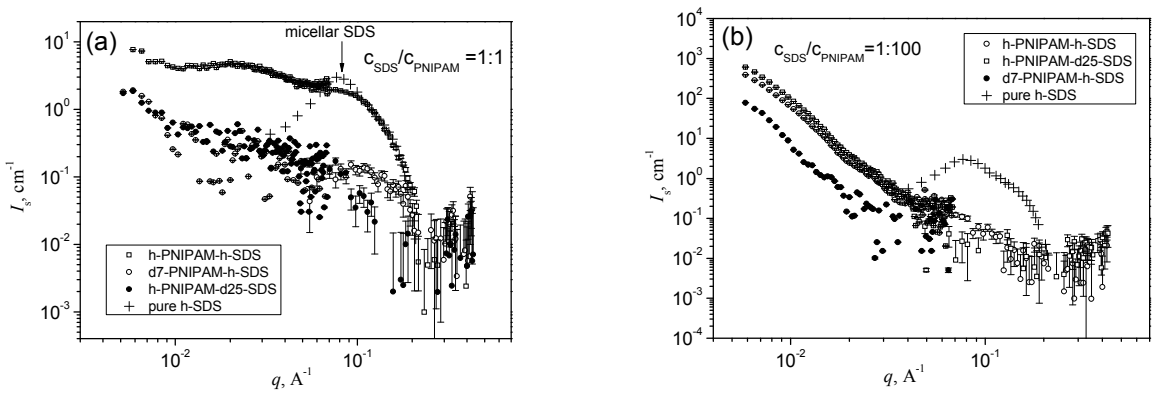

Fig. 5a. Scattered intensity $I_{\mathrm{s}}$ as a function of the scattering vector $q$ for systems PNIPAM/SDS sample CPNIPAM/ CSDS $_{\text {S }} 1: 1, c_{\text {-PNIPAM }}=5 \mathrm{~g} / \mathrm{L}$; (०) d7-PNIPAM/h-SDS; $(\bullet)$ hPNIPAM/d25-SDS; ( $\square$ ) h-PNIPAM/h-SDS; (+) pure SDS. Data are taken from reference (Lee \& Cabane, 1997).

Fig. 5b. Scattered intensity $I_{\mathrm{S}}$ as a function of the scattering vector $q$ for systems PNIPAM/SDS sample CPNIPAM/ $c_{\text {SDS }}=1: 00, c_{\text {-PNIPAM }}=5 \mathrm{~g} / \mathrm{L} ;(\circ)$ h-PNIPAM/h-SDS; $(\bullet)$ d7PNIPAM/h-SDS; (口) h-PNIPAM/d25-SDS; (+) pure SDS. Data are taken from reference (Lee \& Cabane, 1997).

In order to determine the shape and geometric size of the particles we performed Cryo-TEM measurements for the samples at composition 1:100. The Cryo-TEM images are shown in Fig. 6.

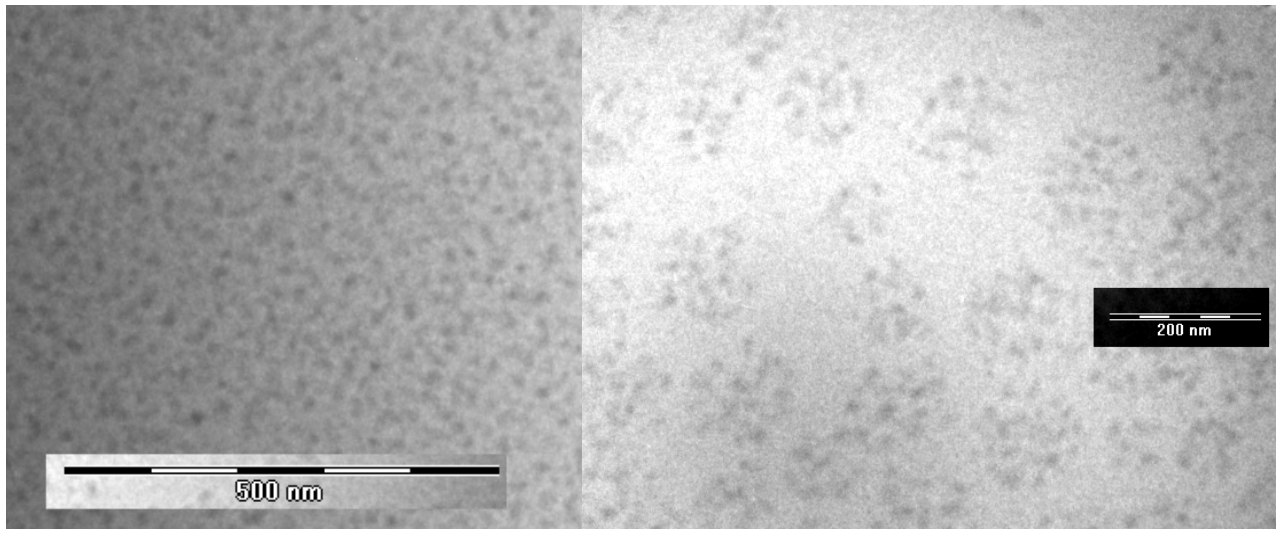

Fig. 6. Cryo-TEM micrographs. h-PNIPAM/h-SDS sample $c_{\text {PNIPAM }}=5 \cdot 10^{-3} \mathrm{~g} \mathrm{~mL}^{-1} ; c_{S D S}=5 \cdot 10^{-5} \mathrm{~g}$ $\mathrm{mL}^{-1} \cdot \mathrm{c}_{\mathrm{SDS}} / \mathrm{c}_{\mathrm{PNIPAM}}=1: 100$

Fig. 6 shows objects thate are rather polydisperse in size. The average size of moieties is in agreement with SANS data, giving value roughly $20-30 \mathrm{~nm}$ in radius. The TEM images are $2 \mathrm{D}$ projection of the particles, observed under different angles. Therefore, we believe that the structures we see in Fig. 6 are of more or less spherical shape. Individual micelles seen in SANS experiments were not imaged in these samples, because of their small size. 


\section{Controlled phase separation induced by a change of solvent}

\subsection{Density}

For a specific polymer/solvent system, phase separation could be induced by a change of the solvent. This particular case of spontaneous macrophase separation leading to formation of nano-sized droplets is frequently referred to as Ouzo effect (Ganachaud \& Katz , 2005), although it has a variety of names. Some authors call this process solvent shifting (Brick et al., 2003; Van Keuren, 2004), solvent displacement(Potineni et al., 2003; Trimaille et al., 2003; Lince et al., 2008; Chu et al., 2008; Vega et al., 2008; Nguyen et al., 2008; Beck-Broichsitter et al., 2009) spontaneous emulsification (Gallardo et al., 1993; QuintanarGuerrero et al., 1997; Baimark et al., 2007; Tan et al., 2008; Katas et al., 2009) or micro/nano precipitation (Leroueil-Le Verger et al., 1998; Peracchia et al., 1999; Bilati et al., 2005; Leo et al., 2006; Legrand et al., 2006). In our previous papers (Panek et al., 2011a; Panek et al., 2011b) we have successfully tested this procedure: polymeric nanoparticles were prepared by mixing a polymer - poly(methyl methacrylate) or polystyrene - dispersed in an organic solvent with an aqueous solution of a surfactant (SDS). Since water is a bad solvent for either of the polymers they start to precipitate but the presence of a surfactant terminates the phase separation and nearly monodisperse nanoparticles appear with a typical size in the range of 50 to $300 \mathrm{~nm}$. Finally the organic solvent is evaporated. We demonstrated that a variety of parameters such as polymer molar mass, surfactant hydrophobicity, solution temperature and composition influence the physico-chemical properties of nanoparticles formed in solution (Panek et al., 2011a; Panek et al., 2011b). Nevertheless, detailed information on nanoparticles structure is still missing.

Here we describe new experiments with static and dynamic light scattering that were conducted to get further insight on the internal structure of the nanoparticles. Using a combination of both methods, for the first time, we calculated such parameters as a structure factor $R_{\mathrm{g}} / R_{\mathrm{h}}$ and density of nanoparticles $(\rho)$. $R_{\mathrm{g}}$ values were measured by static light scattering. In contrast with $R_{\mathrm{h}}$ (Panek et al., 2011a) there is no detectable difference in the factor $\rho=R_{\mathrm{g}} / R_{\mathrm{h}}$ of nanoparticles made from ionic and non-ionic surfactants (Fig. 7).

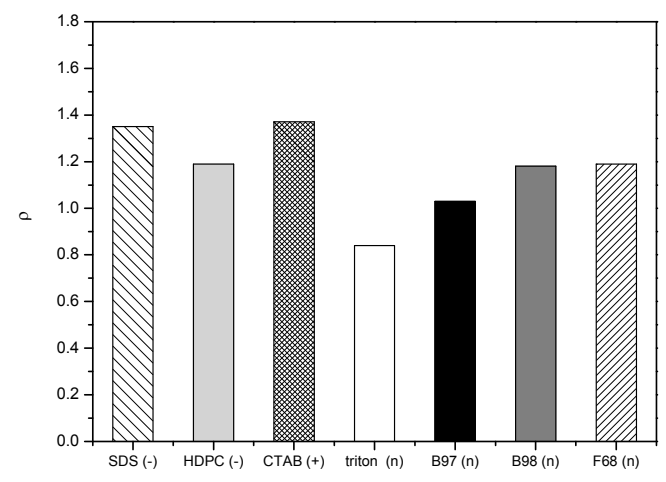

Fig. 7. Histogram of structure factor $\rho=R_{\mathrm{g}} / R_{\mathrm{h}}$ obtained from SLS/DLS data for PMMA(1) $c_{\mathrm{P}}=2 \cdot 10^{-4} \mathrm{~g} \mathrm{~mL}^{-1}$ for various surfactants. 
According to Burchard (Burchard, 1999) this generalized ratio $\rho$ is of special interest for establishing the particle architecture. It is varying in the range 0.8-1.4. The lowest value is for a Triton surfactant, where the particle behaves as a hard sphere ( $\rho$ is close to 0.778 ). The value of $\rho$ for CTAB, SDS, Brij 97 and 98 is about 1.2-1.4. This is characteristic for several models, in particular for branched polymers, soft spheres and dendrimers.

In contrast, the density of nanoparticles is very sensitive to the nature of a surfactant (Fig. 8). The density of nanoparticles was calculated by dividing their mass obtained from static light scattering by their volume based on the $R_{\mathrm{g}}$. Nanoparticles composed of low molecular ionic surfactants have almost two-fold higher density then the ones with polymeric non-ionic surfactants. Since all polymeric surfactants are diblock copolymers, we can assume that polymers can't adopt maximum packing structure due to steric factors.

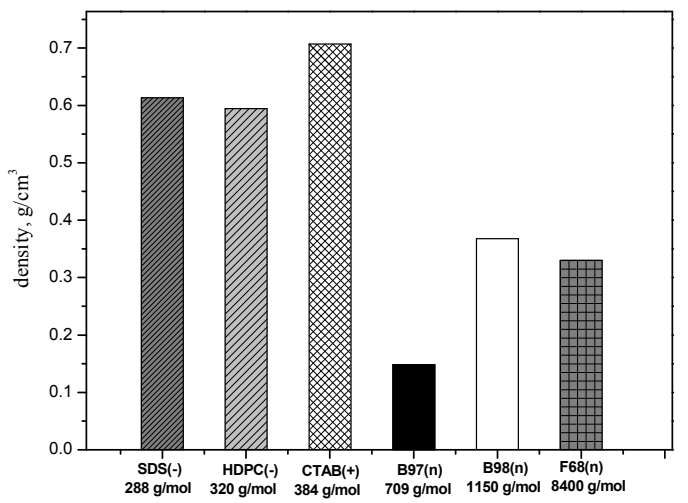

Fig. 8. Histogram of density obtained from SLS/DLS data for PMMA(1) $c_{\mathrm{PMMA}}=2 \cdot 10^{-4} \mathrm{~g}$ $\mathrm{mL}^{-1}$ for various surfactants.

Obviously some voids should be inside. Such conclusion is in agreement with previous SANS and Cryo-TEM (Panek et al., 2011a). Analysis of the SANS curves supports neither a core-shell structure model of the nanoparticles nor a polymeric sphere with surfactant inclusions. Nevertheless a closer inspection of some micrographs reveals the presence of thin white hallo around a nanoparticle. Possible distribution of surfactant inside of a nanoparticle is presented on Fig. 9. The permanent entrapment of a surfactant inside nanoparticle may occur because the polymer (PMMA or PS) is in the glassy state. Plausibility of such scenario has been proven by J. Kriz et al. (Kriz et al., 1996) who demonstrated that the mobility of PS moieties in the core of polystyrene-blockpoly(methacrylic acid) (PS-PMAc) micelles is significantly decreased, which indicates that the polymer including the surfactant inside a micelle is vitrified.

\subsection{Influence of mixing rate}

The effect of mixing rate (i.e. the rate at which the water solution of a surfactant is delivered into the organic solution of a polymer) on the self-assembled nanoparticles formed in the PS/SDS mixed solutions was also investigated (Fig. 10). The molecular weight of PS was varied in the range $0.9-30 \cdot 10^{6} \mathrm{~g} \mathrm{~mol}^{-1}$. At low molecular weights of PS, the mixing rate has 


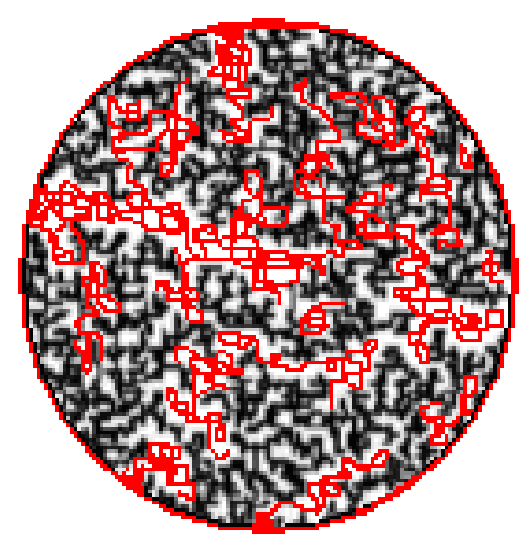

Fig. 9. Possible distribution of a surfactant (red color) and polymer (black color) inside of a nanoparticle by SANS data.

an important influence on the size of nanoparticles. Changing the mixing rate from 0.5 $\mathrm{mL} / \mathrm{min}$ up to $2 \mathrm{~mL} / \mathrm{min}$ makes two times smaller particles. At higher polymer molecular weights the influence of mixing rate is smaller. We conclude that lower mixing rate reduces the number of surfactant molecules in the neighborhood of polymeric nuclei formed after solvent shifting. Smaller number of surfactant molecules slow down stabilization of polymeric nuclei thus leading to forming bigger nanoparticles.

The difference in composition ratio is responsible for molecular weight dependence of nanoparticle dimensions at constant mixing rate and polymer weight concentration (Fig. 10). The bigger molecular weight of a polymer the smaller its molar concentration in mixed solution that leads to a decrease in composition ratio which governs the nanoparticle dimensions. At higher molecular weights of the polymer, the tendency is reverse, showing the growth of sizes (Fig. 10). One of the possible explanations is that macromolecules with

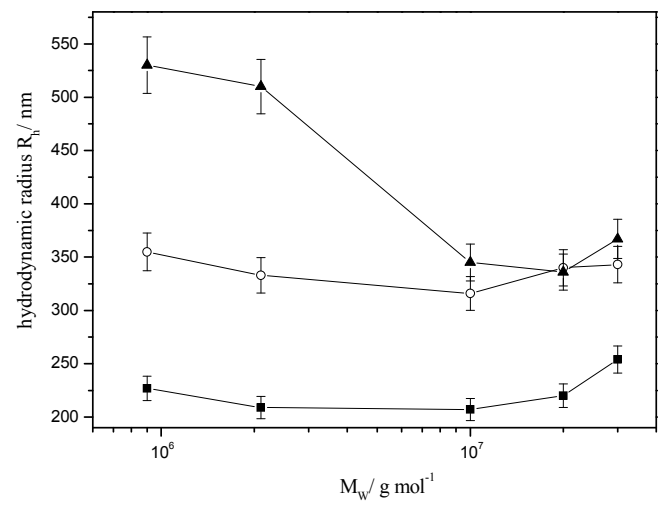

Fig. 10. Dependence of hydrodynamic radius of nanoparticles on molecular weight of polymer for PS $c_{\mathrm{PS}}=2 \cdot 10^{-4} \mathrm{~g} \mathrm{~mL}^{-1}$ and SDS $c_{\mathrm{SDS}}=5 \cdot 10^{-3} \mathrm{~g} \mathrm{~mL}^{-1}$ system at different mixing

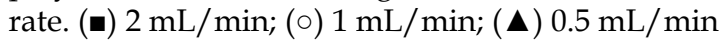


extra large molecular weight have very low diffusion which limits the probability of surfactant molecules to find enough polymer molecules in surroundings. Fast diffusion of water molecules into polymer interface during mixing forms a surfactant-abandoned layer. In these conditions, it's energetically more favorable for a polymer chain to merge with other polymer molecules and form bigger nanoparticles in comparison with solutions of the same surfactant concentration and mixing rate.

The results presented so far show that the self-assembly in the mixed polymer/surfactant systems is rather complex. Mixing of the surfactant solutions with the polymer solutions in organic solvent results in the formation of nanoparticles, whose size can be tuned by changing the relative amounts of surfactant and polymer, as well as mixing rate.

\section{Controlled phase separation induced by a change in $\mathrm{pH}$}

Changing of $\mathrm{pH}$ for a $\mathrm{pH}$ sensitive polymer is another way to construct polymeric nanoparticles. The $\mathrm{pH}$ of the solution is gradually changed so that the polymer which is in the beginning in an environment where it is molecularly soluble (i.e. in the mostly ionized form), starts to precipitate. Adding a surfactant terminates the phase separation in a controlled way leading to formation of well-defined nanoparticles with low polydispersity. We have demonstrated this procedure using a $\mathrm{pH}$-sensitive hydrophobic polymer - i.e. poly(N-methacryloyl-L-valine) (pNMV), the extent of macrophase separation was controlled by the amphiphilic molecule Brij98. We have shown previously (Filippov et al., 2008; Filippov et al., 2010) that in a certain range of concentration and composition of the polymer/amphiphile system very monodisperse particles with size ca. $50 \mathrm{~nm}$ could be reproducibly prepared after a change of $\mathrm{pH}$ from 7 to 3.5. This change is reversible and the nanoparticles can be repeatedly created and dissolved by variation in $\mathrm{pH}$. This type of particles can be very useful, since they may be able to solubilize hydrophobic drugs in large amounts and release them after a change of $\mathrm{pH}$. For example the $\mathrm{pH}$ of stomach is 1 to 3 (nanoparticles associated), while the $\mathrm{pH}$ of duodenum is 7 to 8 (particles dissolved, drug released).

The nucleation of these nanoparticles has not yet been investigated. The early stages of nucleation in such systems determine the nanoscopic structure of the particles that is so far unknown, but important for their envisaged applications. Recently, new technical possibilities to study the kinetics of self-assembly were developed. Primary, it concerns socalled stopped-flow experiments combined with small-angle scattering equipments. (Narayanan et al., 2001; Grillo et al., 2003; Panine et al., 2006). A variety of nanostructures were tested by time-resolved light scattering, SAXS, and SANS. The kinetics of micelles-tovesicles (Schmolzer et al., 2002; Weiss et al., 2005; Weiss et al., 2008; Shen et al., 1989) and lamellar-to-microemulsion (Deen et al., 2009; Tabor et al., 2009) phase transition was studied in details. Another challenging areas for time-resolved experiments are the life time of micelles (Lund et al., 2009) monomers-micelles exchange rate (Eastoe et al., 1998; Tucker et al., 2009), and nucleation of gold (Abecassis et al., 2007; Abecassis et al., 2008) and mineral nanoparticles. (Pontoni et al., 2002; Ne et al., 2003; Bolze et al., 2004). For further details on this topic, the reader is referred to reviews on the application of stopped-flow technique in SANS and SAXS. (Grillo et al., 2009; Gradzielski et al., 2003; Gradzielski et al., 2004) 
We have exploited stopped-flow technique combined with SAXS to monitor early stages of nucleation on the time scale of seconds (Fig. 11). The main difference from solvent-shifting experiments described above is absence of macroscopic fluxes and solution inhomogenuities caused by mixing. In stopped-flow experiments very fast mixing setup provides solution with uniform density where nanoparticles are growing in time.

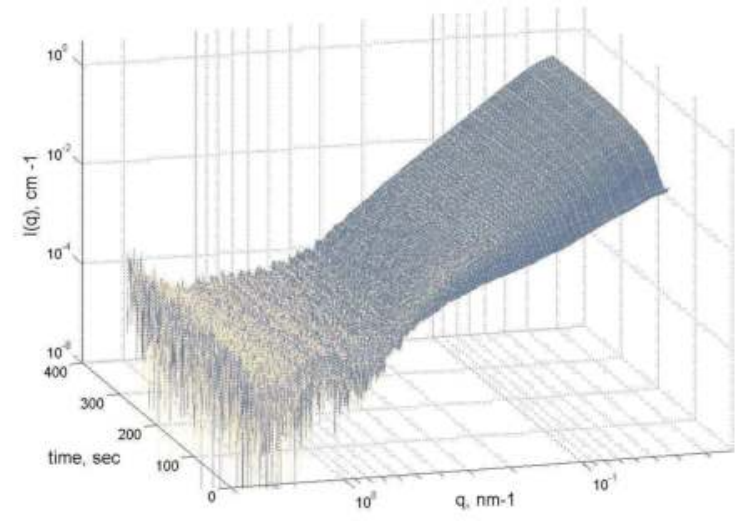

Fig. 11. The temporal evolution of the SAXS intensity for pNMGL $\left(c_{\mathrm{p}} / c_{\text {surf }}=2.0\right)$ system.

The aim of the experiment was to measure the kinetics of self-assembly of $\mathrm{pH}$-sensitive polymeric nanoparticles stabilized by surfactants. The four types of $\mathrm{pH}$-sensitive hydrophobic polymers that have been used in our research for the growth of nanoparticles were: (a) poly(N-methacryloyl-L-valine) (pNMV); (b) poly(N-methacryloyl glycyl-Lphenylalanyl-L-leucinyl-glycine) (pNMGPLG), and (c) poly(N-methacryloyl glycyl-Lleucine) (pNMGL). The extent of macrophase separation was controlled by the surfactants Brij 97, and Brij 98. The surfactants were different in the length of hydrophilic PEO chain.

\subsection{The self-assembly of nanoparticles}

Fig. 11 displays the intensity of scattered X-rays from the mixture of aqueous solution of Brij 98 surfactant and pNMGL $\left(c_{\mathrm{p}} / c_{\text {surf }}=2.0\right)$ solution as a function of time. The SAXS technique is commonly used to extract information on molecular architecture and size of nano-objects in solution that can be performed by the analysis of Kratky or Guinier plots.(Glatter \& Kratky , 1982) The scattering from nanostructures reveals three regions in the dependence of scattering intensity on scattering vector, $I \sim q^{\alpha}$ with different behaviors characteristic for the various length scales. At low $q$-range, the "Guinier" regime $\left(q R_{\mathrm{g}}<1\right)$ is usually attained. Middle $q$-range is usually sensitive to the shape of the scattering object; $a=-4$ stands for hard spheres, -2 stands for planar objects, and $a=-1$ stands for rod-like structures. It was proved experimentally that in some cases, the a value in middle $q$-range is not integral but rather fractional. This situation corresponds to the so-called fractal structure. In the high $q$ range, local stiffness of macromolecules (due to shorter length scales probed) can be revealed with $I(q) \sim q^{-1}$. Nanoparticles with sharp interface and smooth surface obey a $q^{-4}$ law that is usually referred to as „Porod" behavior. 
Several things should be noted. $I(q)$ value at the lowest experimental $q$ grows with time, which is clearly an indication of particle growth (Fig. 11). For the highest composition ratio $\mathrm{C}_{\mathrm{Brij}} 8 / \mathrm{C}_{\mathrm{pNMGL}}=2.0$, in the middle $q$-range, the exponent value $\mathrm{a}$ is growing from -2.2 at the beginning up to -3.4 for the longer time (Fig. 12). The $q^{-2.2}$ dependence of $I(q)$ observed on early stages of self-assembly is attributed to the scattering from a loose, fractal structure. In contrast, a value of -3.4 suggests large compact objects. Thus using TRSAXS we can monitor the self-assembly of nanoparticles when particles transform through fractal structure with loose surface into hard spheres with sharp interface.

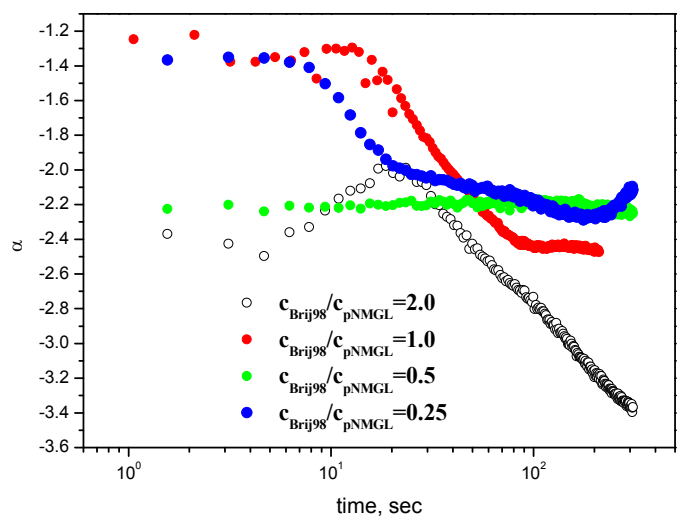

Fig. 12. The temporal evolution of the exponent value a for a pNMGL-Brij 98 system at different composition ratio $\mathrm{c}_{\mathrm{Brij}} \mathrm{g} / \mathrm{c}_{\mathrm{pNMGL}}$.

For the lowest composition ratio $c_{B r i j} 8 / c_{p N M G L}=0.25$, the behavior changes greatly. $I(q)$ value at the lowest $q$ as well as the a exponent do not evolve with time (Fig. 12). Obviously, nanoparticles have been already formed prior to the first measurement. Those nanoparticles do not have sharp boundaries and have fractal structure that is a characteristic for loose entities. Surfactant molecules are not enough to cover the whole nanoparticles.

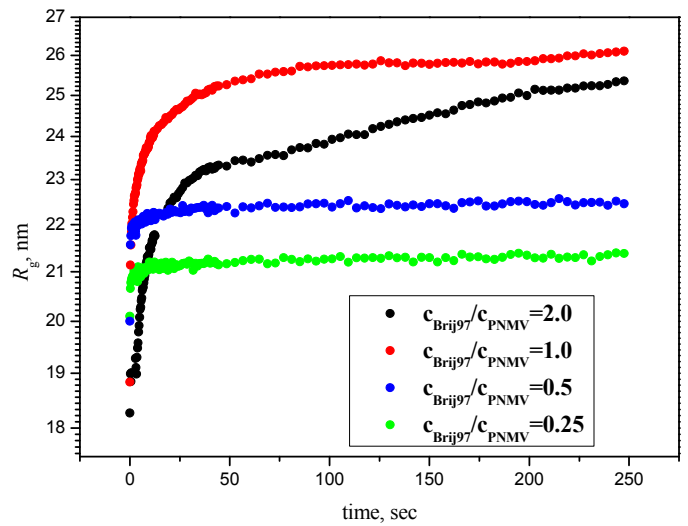

Fig. 13. The temporal evolution of the exponent value a for a pNMV -Brij 97 system at different composition ratio $\mathrm{c}_{\mathrm{Brij}} \mathrm{f} / \mathrm{c}_{\mathrm{pNMV}}$. 
To extract further information on the kinetics of nanoparticle formation, the radius of gyration was calculated and compared for different polymers and surfactants. The results are shown in Fig. 13-15. We observe that the radius strongly depends on the composition ratio. Moreover, two distinct regimes separated in time can be observed. During the first seconds, there is a rapid increase in the $R_{\mathrm{g}}$ value. This behavior could be explained as a nucleation regime when preliminary nuclei are formed. After a short period of time that depends also on composition ratio, the $R_{\mathrm{g}}$ value of nanoparticles increases by consumption of the remaining surfactant molecules in solution, thus defining the growth regime. The higher the composition ratio, the growth regime is more expressive (Fig. 13, 14). Nevertheless, sometimes a decrease in $R_{\mathrm{g}}$ is observed at the first seconds. We can assume that such scenario could be realized when several aggregates of pearl-necklace micelles disassembling prior to formation of original nuclei.

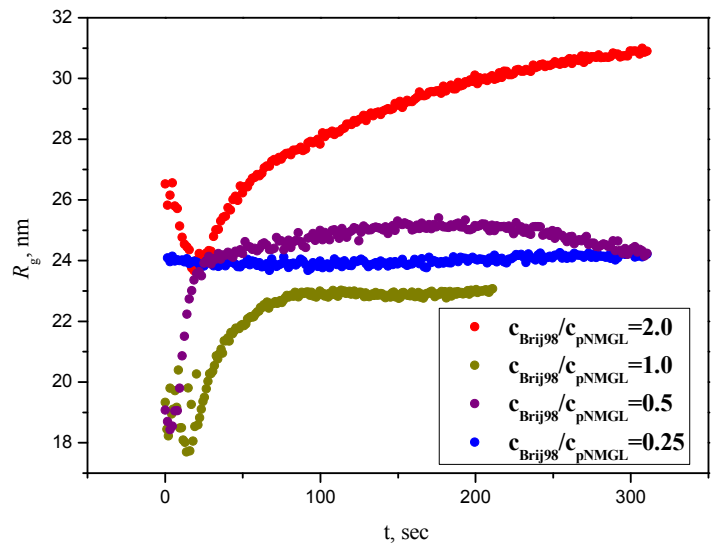

Fig. 14. The temporal evolution of the exponent value a for a pNMV-Brij 98 system at different composition ratio $\mathrm{C}_{\mathrm{Brij}} \mathrm{g} / \mathrm{C}_{\mathrm{pNMGL}}$.

The conclusion that the growth regime is governed by a surfactant only is further supported from a comparison of kinetic curves of different polymers but the same composition ratio (Fig. 15). The polymers of different nature but the same surfactant (Brij 98) and composition ratio (1.0) could be arranged into a master-curve (inset of Fig. 15). 
In contrast, the system with Brij 97 (red circles) is undoubtedly couldn't be superimposed into the master curve. We conclude that the number and hydrophobicity of monomeric units of a polymer determine the final size of a nanoparticle whereas the growth nucleation rates are controlled by the nature and amount of a surfactant.

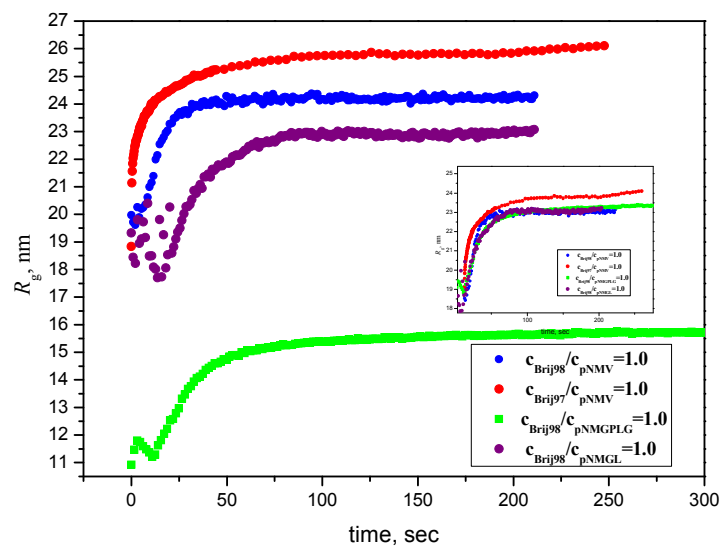

Fig. 15. The temporal evolution of the exponent value a for a pNMV, pNMGL, and pNMGPLG +Brij 98, 97 system at composition ratio 1.0. Inset: master curve.

\section{General conclusions}

We have systematically investigated nanoparticles prepared by controlled phase separation approach. On the basis of our research we have established that the most important parameter for steady-state nanoparticles dimensions is the composition ratio $c$ (surfactant)/c(polymer). Our study demonstrates that full grown nanoparticles have a spherical shape. For the first time we have investigated the architecture of nanoparticles prepared by the solvent shifting method. The density, and factor $\rho=R_{\mathrm{g}} / R_{\mathrm{h}}$ measurement together with SANS experiment shows that nanoparticles are entities with uniform density and without internal structure. Polymeric and surfactant molecules are evenly distributed within a nanoparticle.

When macroscopic non-equilibrium hydrodynamic forces are involved into nanoparticle formation, the nature of the surfactant, its hydrophobicity and charge, insignificantly influences the nanoparticles sizes. A mixing rate is of primary importance for that case.

When hydrodynamic fluxes are eliminated by fast mixing again, the surfactant/polymer composition ratio is of primary importance in nanoparticle formation, thus confirming previous results. Excess of a surfactant results in much faster kinetics in comparison with the solution where a polymer is in excess. Our results suggest that the formation of the 
nanoparticles is a two stage process. In the beginning a nucleation stage occurs followed by a growth regime. The hydrophilicity/hydrophobicity of surfactants plays an important role in the formation of nanoparticles.

\section{Acknowledgements}

We gratefully acknowledge the European Synchrotron Radiation Facility (Grenoble, France) for the provision of synchrotron beam time (SC2883 and SC3113). This work was supported by the Grant Agency of the Czech Republic (202/09/2078) and also by Grant No. IAA400500805 of the Grant Agency of the Academy of Sciences of the Czech Republic. Also, we would like to thank Prof. Katarina Edwards and Dr. Goran Karlsson, Uppsala University, Department of Physical and Analytical Chemistry for help with Cryo-TEM experiments.

\section{References}

Abecassis, B., Testard, F., Spalla, O. \& Barboux, P. (2007). Probing in situ the nucleation and growth of gold nanoparticles by small-angle x-ray scattering. Nano Letters Vol. 7, pp. 1723-1727.

Abecassis, B., Testard, F., \& Spalla, O. (2008). Gold nanoparticle superlattice crystallization probed in situ. Physical Review Letters, Vol. 100, pp. 115504.

Aseyev, V., Hietala, S., Laukkanen, A., Nuopponen, M., Confortini, O., Du Prez, F.E. \& Tenhu, H. (2005). Polymer, Vol. 46, pp. 7118-7131.

Aseyev, V., Tenhu, H. \& Winnik, F. (2010). Non-ionic Thermoresponsive Polymers in Water, Self Organized Nanostrcutures of Amphiphilic Block Copolymers. Springer Berlin Heidelberg, pp. 1-61. (Advances in Polymer Science).

Baimark, Y., Srisaard, M., Threeprom J. \& Narkkong, N. A. (2007). Colloid and Polymer Science, Vol. 285, pp. 1521-1525.

Beck-Broichsitter, M., Gauss, J., Packhaeuser, C.B. , Lahnstein, K. , Schmehl, T. , W. Seeger, T. Kissel \& T. Gessler, (2009). International Journal of Pharmaceutics, Vol. 367, pp. 169178.

Bilati, U., Allemann, E. \& Doelker, E. (2005). European Journal of Pharmaceutical Sciences, Vol. 24, pp. 67-75.

Bolze, J., Pontoni, D., Ballauff, M., Narayanan, T., \& Colfen, H. (2004). Time-resolved SAXS study of the effect of a double hydrophilic block-copolymer on the formation of $\mathrm{CaCO}_{3}$ from a supersaturated salt solution. Journal of Colloid and Interface Science, Vol. 277, pp. 84-94.

Brick, M. C., Palmer, H. J. \& Whitesides T. H. ( 2003). Langmuir, Vol. 19, pp. 6367-6380.

Burchard, W. (1999) Adv Polym Sci, Vol. 143, pp. 113-194.

Chu, B. S. , Ichikawa, S. , Kanafusa S. \& Nakajima, M. (2008). Journal of the Science of Food and Agriculture, Vol. 88, pp. 1764-1769.

Deen, G.R., Oliveira, C.L.P. \& Pedersen, J.S. (2009). Phase Behavior and Kinetics of Phase Separation of a Nonionic Microemulsion of C12E5/Water/1-Chlorotetradecane upon a Temperature Quench. Journal of Physical Chemistry B, Vol. 113, pp. 71387146 . 
Eastoe, J., Dalton, J.S., Downer, A., Jones, G. \& Clarke, D. (1998). Breakdown kinetics of fluorocarbon micelles studied by stopped-flow small-angle X-ray scattering. Langmuir, Vol. 14, pp. 1937-1939.

Filippov, S., Hruby, M., Konak, C., Mackova, H., Spirkova, M. Stepanek, P. (2008). Langmuir, Vol. 24, pp. 9295- 9301.

Filippov, S., Starovoytova, L., Koňák, C., Hrubý, M., Macková, H., Karlsson, G. \& Štěpánek, P. (2010). Langmuir, vol. 26, pp. 14450-14457

Gallardo, M. , Couarraze, G. , Denizot, B., Treupel, L. , Couvreur P., and Puisieux, F. (1993). International Journal of Pharmaceutics, Vol. 100, pp. 55-64.

Ganachaud, F. \& Katz, J.L. (2005). Chemphyschem, Vol. 6, pp. 209-216.

Glatter, O. \& Kratky, O. (1982) Small-Angle X-ray Scattering. London: Academic Press

Gradzielski, M. (2003). Kinetics of morphological changes in surfactant systems. Current Opinion in Colloid \& Interface Science, Vol. 8:, pp. 337-345.

Gradzielski, M. (2004). Investigations of the dynamics of morphological transitions in amphiphilic systems. Current Opinion in Colloid \& Interface Science, Vol. 9, pp. 256263.

Grillo, I., Kats, E.I. \& Muratov, A.R. (2003). Formation and growth of anionic vesicles followed by small-angle neutron scattering. Langmuir, Vol.19, pp. 4573-4581.

Grillo, I. (2009). Applications of stopped-flow in SAXS and SANS. Current Opinion in Colloid $\mathcal{E}$ Interface Science, Vol 14, pp. 402-408.

Jakeš, J. (1995). Collect. Czech. Chem. C, Vol. 60, pp. 1781-1797.

Katas, H. , Cevher E. \& Alpara H. O. (2009). International Journal of Pharmaceutics, Vol. 369, pp. 144-154

Koňák, C., Pánek, J. \& Hrubý, M. (2007). Colloid Polym Sci. Vol. 285, pp. 1433-1439.

Kriz, J., Masar, B., Pospisil, H., Plestil, J., Tuzar Z. \& Kiselev, M.A. (1996). Macromolecules, Vol. 29, pp. 7853-7858

Kujawa, P., Tanaka, F. \& Winnik, FM. (2006). Macromolecules, Vol. 39, pp. 3048-3055

Kujawa, P., Aseyev, V., Tenhu, H. \& Winnik, FM. (2006). Macromolecules , Vol. 39, pp. 76867693

Lee, L.T. \& Cabane, B. (1997). Macromolecules, Vol. 30, pp. 6559-6566

Lince, F., Marchisio D. L. \& Barresi A. A. (2008). Journal of Colloid and Interface Science, Vol. 322, pp. 505-515.

Lund, R., Willner, L., Monkenbusch, M., Panine, P., Narayanan, T., Colmenero, J. \& Richter, D. (2009). Structural Observation and Kinetic Pathway in the Formation of Polymeric Micelles. Physical Review Letters, Vol. 102, pp.188301

Leroueil-Le Verger, M., Fluckiger, L., Kim, Y. I. , Hoffman M. \& Maincent, P. (1998). European Journal of Pharmaceutics and Biopharmaceutics, Vol. 46, pp. 137-143.

Leo E., Scatturin, A., Vighi E., \& Dalpia A. (2006). Journal of Nanoscience and Nanotechnology, Vol. 6, pp. 3070-3079.

Legrand, P., Lesieur, S., Bochot, A., Gref, R., Raatjes, W., Barratt G. \& Vauthier C. (2006). Conference on New Trends in Drug Delivery Systems, Paris, FRANCE.

Narayanan, T., Diat, O. \& Bosecke, P. (2001). SAXS and USAXS on the high brilliance beamline at the ESRF. Nuclear Instruments $\mathcal{E}$ Methods in Physics Research Section a- 
Accelerators Spectrometers Detectors and Associated Equipment, Vol. 467, pp. 10051009

Ne, F., Testard, F., Zemb T, \& Grillo, I. (2003). How does ZrO2/surfactant mesophase nucleate? Formation mechanism. Langmuir, Vol.19, pp. 8503-8510.

Nguyen, J. , Steele, T. W. J., Merkel, O., Reul R. \& Kissel, T. (2008). Journal of Controlled Release, Vol. 132, pp. 243-251.

Pánek, J., Filippov, S.K. , Koňák, Č.,Nallet, F., Noirez, L., Karlsson, G. \& Štěpánek, P. (2011). Journal of Dispersion Science and Technology, Vol. 32, N. 6, pp. 888-897

Pánek, J., Filippov, S.K., Koňák, C., Steinhart, M. \& Štěpánek, P. (2011). Journal of Dispersion Science and Technology, Vol. 32, N. 8, pp. 1105-1110

Panine, P., Finet, S., Weiss, T.M. \& Narayanan, T. (2006). Probing fast kinetics in complex fluids by combined rapid mixing and small-angle X-ray scattering. Advances in Colloid and Interface Science, Vol. 127, pp. 9-18.

Peracchia, M. T., Fattal, E., Desmaele, D. , Besnard, M., Noel, J. P. , Gomis, J. M. , Appel, M. , d'Angelo J. \& Couvreur P. (1999). Journal of Controlled Release, Vol. 60, pp. 121-128.

Potineni, A., Lynn, D. M., Langer R. \& Amiji, M. M. (2003). Journal of Controlled Release, Vol. 86, pp. 223-234.

Pontoni, D., Narayanan, T., \& Rennie AR (2002). Time-resolved SAXS study of nucleation and growth of silica colloids. Langmuir, Vol. 18, pp. 56-59.

QuintanarGuerrero D., Allemann, E., Doelker E. \& Fessi, H. (1997). Colloid and Polymer Science, Vol. 275, pp. 640-647.

Schmolzer, S., Grabner, D., Gradzielski, M. \& Narayanan T (2002). Millisecond-range timeresolved small-angle $x$-ray scattering studies of micellar transformations. Physical Review Letters, Vol. 88, pp. 258301

Shen, L., Du, J.Z., Armes, S.P. \& Liu, S.Y. (1989). Kinetics of pH-induced formation and dissociation of polymeric vesicles assembled from a water-soluble zwitterionic diblock copolymer. Langmuir, Vol. 24, pp.10019-10025.

Siu, M.H., He, C. \&Wu C. (2003). Macromolecules, Vol. 36, pp. 6588-6592

Tabor, R.F., Eastoe, J. \& Grillo, I. (2009) Time-resolved small-angle neutron scattering as a lamellar phase evolves into a microemulsion. Soft Matter, Vol. 5, pp. 21252129.

Trimaille, T. , Chaix, C., Pichot C. \& Delair, T. (2003). Journal of Colloid and Interface Science, Vol. 258, pp. 135-145.

Tucker, I., Penfold, J., Thomas, R.K. \& Grillo, L. (2009). Monomer-Aggregate Exchange Rates in Dialkyl Chain Cationic-Nonionic Surfactant Mixtures. Langmuir, Vol. 25, pp. 2661-2666.

Van Keuren, E. R. (2004). Journal of Dispersion Science and Technology, Vol. 25, pp. 547-553.

Vega, E. , Gamisans, F., Garcia, M. L, Chauvet, A., Lacoulonche F. \& Egea, M. A. (2008). Journal of Pharmaceutical Sciences, Vol. 97, pp. 5306-5317

Weiss, T.M., Narayanan, T., Wolf, C., Gradzielski, M., Panine, P., Finet, S. \& Helsby, W.I. (2005). Dynamics of the self-assembly of unilamellar vesicles. Physical Review Letters, Vol. 94, pp. 038303. 
Weiss, T.M., Narayanan, T. \& Gradzielski, M. (2008). Dynamics of spontaneous vesicle formation in fluorocarbon and hydrocarbon surfactant mixtures. Langmuir, Vol. 24, pp. 3759-3766.

Yan, C. H. , Yuan, X. B., Kang, C. S., Zhao, Y. H. , Liu, J., Guo, Y. S. , Lu, J. , Pu P. Y. \& Sheng J. (2008). Journal of Applied Polymer Science, Vol. 110, pp. 2446-2452. 


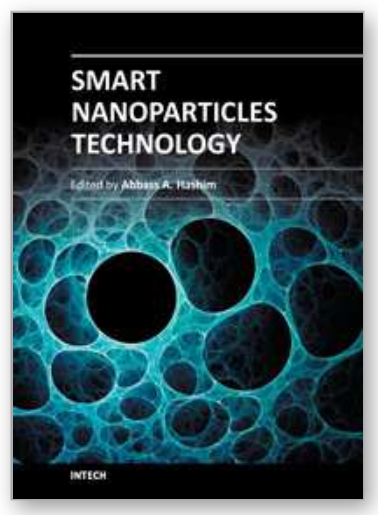

\author{
Smart Nanoparticles Technology \\ Edited by Dr. Abbass Hashim
}

ISBN 978-953-51-0500-8

Hard cover, 576 pages

Publisher InTech

Published online 18, April, 2012

Published in print edition April, 2012

In the last few years, Nanoparticles and their applications dramatically diverted science in the direction of brand new philosophy. The properties of many conventional materials changed when formed from nanoparticles. Nanoparticles have a greater surface area per weight than larger particles which causes them to be more reactive and effective than other molecules. In this book, we (InTech publisher, editor and authors) have invested a lot of effort to include 25 most advanced technology chapters. The book is organised into three well-heeled parts. We would like to invite all Nanotechnology scientists to read and share the knowledge and contents of this book.

\title{
How to reference
}

In order to correctly reference this scholarly work, feel free to copy and paste the following:

Sergey K. Filippov, Jiri Panek and Petr Stepanek (2012). Polymeric Nanoparticles Stabilized by Surfactants: Controlled Phase Separation Approach, Smart Nanoparticles Technology, Dr. Abbass Hashim (Ed.), ISBN: 978-953-51-0500-8, InTech, Available from: http://www.intechopen.com/books/smart-nanoparticlestechnology/polymeric-nanoparticles-stabilized-by-surfactants-controlled-phase-separation-approach-

\section{INTECH}

open science | open minds

\section{InTech Europe}

University Campus STeP Ri

Slavka Krautzeka 83/A

51000 Rijeka, Croatia

Phone: +385 (51) 770447

Fax: +385 (51) 686166

www.intechopen.com

\section{InTech China}

Unit 405, Office Block, Hotel Equatorial Shanghai

No.65, Yan An Road (West), Shanghai, 200040, China 中国上海市延安西路65号上海国际贵都大饭店办公楼 405 单元

Phone: +86-21-62489820

Fax: $+86-21-62489821$ 
(C) 2012 The Author(s). Licensee IntechOpen. This is an open access article distributed under the terms of the Creative Commons Attribution 3.0 License, which permits unrestricted use, distribution, and reproduction in any medium, provided the original work is properly cited. 